Bangladesh J. Zool. 40(1): 1-11, 2012

\title{
POPULATION STUDIES OF TREE HOLE BREEDING AEDES SPECIES (DIPTERA: CULICIDAE) IN DHAKA UNIVERSITY CAMPUS AND ITS ADJACENT SUHRAWARDI PARK, DHAKA CITY, BANGLADESH
}

\author{
Nargis Sultana, Tangin Akter and Shefali Begum* \\ Department of Zoology, University of Dhaka, Dhaka-1000, Bangladesh
}

\begin{abstract}
A survey of the larval population of tree hole breeding Aedes mosquito was conducted from January to December, 2010 in four different areas of Dhaka University Campus and its adjacent Suhrawardi park. A total of 689 mosquito larvae was collected during the survey. Among them 396 (57.47\%) were Aedes albopictus, 51 (7.02\%) were Ae. aegypti and 242 (35.12\%) other Aedes species, and the number of male and female among them was counted $347(50.36 \%)$ and 342 $(49.63 \%)$, respectively. Among the varieties of plant species in the study area only 27 species of trees were found with 56 holes wherein 34 holes of 17 species trees were used by mosquitoes for breeding ground. The highest number (160) of larvae was found in bamboo (Bambusa nutans) stumps hole and lowest (13) in Delonix regia hole. The highest number of larval population was collected in September and the larval population increased from March to September and then gradually decreased. No mosquito larva was found in the tree holes in January and February. The number of larvae collected from different survey areas also varied which were 309 (44.84\%), 152 (22.06\%), 145 (21.04\%) and 83 (12.04\%) in Suhrawardi park, and the Arts building, Curzon hall and Botanical garden of Dhaka University, respectively.
\end{abstract}

Key words: Tree hole, Aedes, seasonal variation, Dhaka City.

\section{INTRODUCTION}

Mosquitoes under the genus Aedes are responsible for the transmission of arbovirus which cause diseases like dengue and yellow fever (Cordellier et al. 1977). Dengue is found in tropical and sub-tropical regions around the world, predominately in urban and peri-urban areas. Dengue haemorrhagic fever (DHF) was first recognized during the 1950s and is today a leading cause of childhood mortality in several Asian countries (Rahman et al. 2002).

Large-scale yearly outbreaks during the rainy season have been occurring in Bangladesh since the year 2000 (Ahmad 2000, Rahman et al. 2002, Rasul et al. 2002). Dengue infection was previously uncommon in this country. An outbreak of dengue occurred in 1964, and was labeled as 'Dacca Fever'. (Russell et al. 1966, Aziz et al. 1967).

Aedes aegypti (L.) is a well known vector of dengue and chikungunya viruses in the tropical and sub tropical regions. Ae. aegypti mosquitoes are the most important and the primary domestic vector of urban dengue and yellow fever viruses (Gubler 1998, 2001). Ae. aegypti can also transmit filarial infections of

*Corresponding author. 
Wuchereria sp. and Dirofilaria immitis (Russel et al. 2005) and avian parasite Plasmodium gallinaceum (Alavi et al. 2003). They enter buildings to feed and prefer to lay their eggs in artificial containers (Christopher 1960). However, Ae. aegypti utilize natural available breeding sites as the tree holes and leaf axils of the plants of the family Bromeliaceae (Lee et al. 1987).

Ae. albopictus ranks just second to Ae. aegypti in human health impact as a vector of dengue (Knudsen 1995) and it can transmit efficiently numerous arboviruses as well as Dirofilaria sp. (Gratz 2004).

Ae. albopictus is a tree hole mosquito; its breeding places in nature are small, restricted, shaded bodies of water surrounded by vegetation. The addition of decaying leaves from the neighboring trees produces chemical conditions similar to tree holes, which provide an excellent substrate for breeding. Ae. albopictus can also establish and survive throughout non-urbanized areas lacking any artificial containers, raising additional public health concerns for rural areas (Moore 1999, Eritja et al. 2005).

The occupancy of artificial containers, human facilitated transport, desiccation-resistant eggs, and associations with human habitats enable two important dengue vectors, Ae. aegypti and Ae. albopictus, to become cosmopolitan (Lounibos 2002). Juliano et al. (2002) proposed that local coexistence of the species is possible because warm dry climates favor Ae. aegypti by alleviating the effects of competition from Ae. albopictus through differential mortality of Ae. albopictus eggs. Coexistence of the species observed in tropical Asia might be also caused by this phenomenon. In these regions of sympatry, Ae. aegypti and Ae. albopictus rarely share identical habitats in southeast Asia (Hawley 1988). There, the former species is more often found in urban habitats where it oviposits indoors (Thavara et al. 2001, Harrington et al. 2001), whereas the latter species is commonly found in less urbanized habitats with more outdoor larval sites (Hawley 1988, Thavara et al. 2001). The displacement of Ae. albopictus by Ae. aegypti in certain Asian cities was suggested to be caused by the destruction of Ae. albopictus habitats with a concomitant increase in urban habitat more suitable for Ae. aegypti (Chan et al. 1971, Hawley 1988).

The Dhaka University Campus has many different types of plants and some of these plants have different sizes of holes which contain water during rainy season. These holes are suitable habitats for insects like mosquitoes having a larval stage in water. There is few reports on the population studies of Aedes species in Dhaka University Campus and few results are available on the tree hole breeding situation of Ae. aegypti. The objectives of the present study were: to look into the monthly variations of Aedes sp. and their distribution in four different areas of Dhaka University Campus and adjacent Suhrawardi park. 


\section{MATERIAL AND METHODS}

The present survey was conducted from January to December 2010.

Locations for sample collection: Dhaka University is situated in the center of Dhaka Metropolitan City. Four different areas of the University Campus were selected for the collection of mosquito sample. The selected locations were Curzon Hall Campus, Botanical Garden, Arts Faculty Campus of the University and adjacent Suhrawardi Park.

Curzon Hall Campus area: It is situated just opposite to the old High Court. There are many trees, such as Mimusops elengi, Litchi chinenses, Ravenala madagascariensis, Artocarpus heterophyllus, Artabotyris uncinatus, Michelia champaca, Lagerstroemia speciosa, Alstonia scholaris and Bambusa nutans (bamboo) in this Campus. Some of these trees have holes and stumps. These holes and stumps act as the breeding places of mosquitoes.

Botanical garden: It is located on the Curzon Hall premises. It partially serves the purposes of teaching to the university student. There was some bushy flower, ornamental plants and large trees, such as Cycas revolute, Mangifera indica, Pinus longifolia, Disopyros peregrine, Hevea brasiliensis, Barringtonia acutangula and Aquillaria agollocha. The holes of some of these trees are filled up with rain water during rainy season and become suitable for mosquito breeding.

Arts Faculty Campus: This campus is situated near the Nilkhet area. There are large number of trees, such as Mangifera indica, Artocarpus heterophyllus, Delonix regia, Albizzia richardiana, Litchi chinenses, and other trees. Some of these trees contain holes which are of different sizes.

Suhrawardi park: This park begins near the old High Court and stretching all the way to the National Museum at Shahbagh. It has a large number of trees, such as Artocarpus heterophyllus, Anthocephalus chinensis, Delonix regia, Mangifera indica, Musa sapientum, Litchi chinenses, Diospyros peregrine, Mimusops elengi, Nyctanthes arbor tristis, Callistemon citrinus, Ployalthia longifolia, Artabotyris uncinatus, Hevea brasiliensis, Alstonia scholaris, Lagerstroemia speciosa, Tamarindus indica, Albizzia richardiana, Barringtoni acutangula, Phyllanthus emblica, Syzygium jambos, etc. Some of these trees contain holes and are suitable for mosquito breeding.

The climate of Dhaka City is characterized by moderately high temperature prevailing about eight months in the year and humidity is high with heavy rainfall in summer. The season may be divided into three main heading (Ahmed 1987).

Sample collection: The breeding sources included tree holes of different trees and bamboo stumps. In dry condition, that is no water was present inside the 
tree holes, the soil materials or debris were collected from the tree holes with the help of a large spoon. Then, the samples were put into plastic bags. During the rainy season, the tree holes were filled up with rain water. In some cases, the tree holes water contained mosquito larvae. In that case the larvae were collected with the help of a siphon and then transferred the sample into plastic bags. All of the bags were properly labeled and were brought to the Entomological laboratory, Department of Zoology, University of Dhaka. The sampling was usually conducted at the time between 10 a.m and12 noon.

Processing of the samples: A jute bag or poly bag was used to transport the collected samples from the field to the laboratory. In the laboratory, the samples were transferred into a plastic bowl, then it was covered with a piece of fine mosquito net. The samples were observed every day for detecting the hatching of the eggs. In the case of dry sample, water was added for the hatching of the eggs. After hatching, the larvae were counted for each collection site and then transferred into a single vial with water and allowed for further development.

Larval differentiated Characters: After the larvae hatched from the eggs, they were developed into $4^{\text {th }}$ instar. Then the larvae were placed on slides with a few drops of water and were examined under a compound binocular microscope. The two Aedes sp. were identified according to the method of Cheong (1986) and WHO (1995). After examination the larvae of Aedes sp. were placed in a until adult emergence. The numbers of adult male and female mosquitoes emerged were recorded.

\section{RESULTS AND DISCUSSION}

The monthly collection data of mosquito larvae from Curzon Hall area, Botanical Garden and Arts Faculty Campus of Dhaka University and Suhrawardi Park are presented in Table 1. The result showed that Ae. aegypti, Ae. albopictus and other Aedes species constituted 8.27, 60.68, 31.03\%, respectively in Curzon Hall Campus; 10.84, 50.60, 38.55\%, respectively in Botanical Garden; 5.26, 58.55, 36.18\%, respectively in Arts Faculty Campus and $7.11,57.28,35.59 \%$, respectively in Suharwardi Park.

The monthly distribution of different species of Aedes obtained from the tree holes were: $21.04 \%$ (145) in the Curzon Hall, $12.04 \%$ (83) in the Botanical Garden of Curzon Hall Campus, 22.06\% (152) in the Arts Faculty Campus and 44.84\% (309) in the Suhrawardi Park. The highest number of Aedes mosquitoes was found during the month of September. No mosquito larvae were found in January and February. The same results were observed where the number of mosquito positive houses was higher and significantly different in wet season than in dry season (Ahmed et al. 2007). 


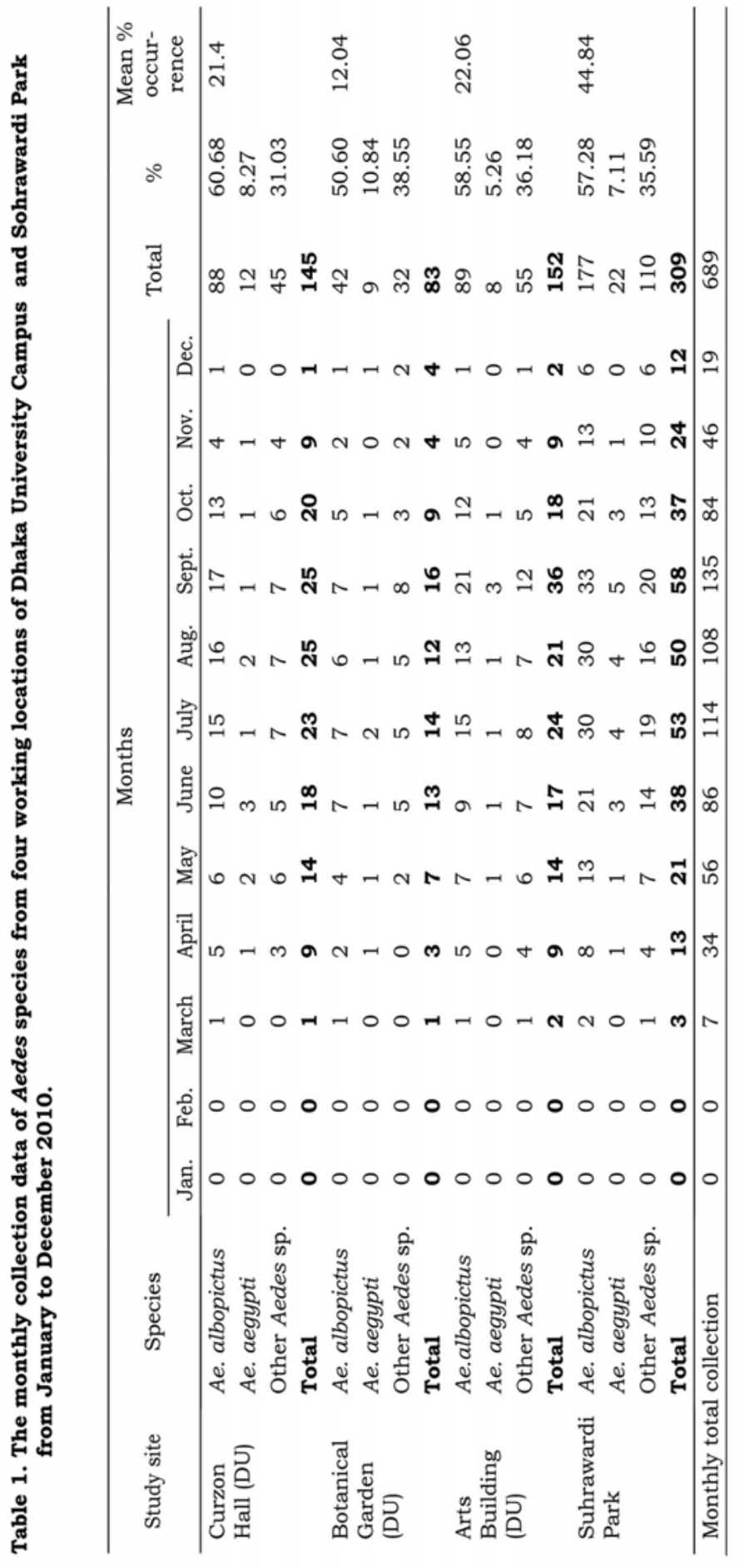


Khan (1980) studied the breeding habitats and seasonal prevalence of the larval population of Ae. aegypti and Ae. albopictus in Dhaka City. He encountered a total of two species of mosquito larvae from different types of containers, e.g. tyres, tin cans, glass receptacles, flower pots/vases, axils of leaves, metal pots, tree holes, coconut shells and temporary water in mud. He found that during the rainy season from May to October 1977, the population of Ae. aegypti and Ae. albopictus remained high. As the dry season approached with the decline of rainfall from November, their population started declining until January 1978. The driest three months January, February and March 1978 resulted in zero larval population. During the present study the driest period (January and February) resulted in zero larval population.

Khan (1980) also found that nine out of 10 locations of Dhaka City remained infested with the larvae of either one or both species of Aedes mosquito during the rainy season. As the dry season approached, the infestation started declining with the driest three months without any breeding. Ae. albopictus was present in eight locations. On the other hand, Ae. aegypit was present in only five locations. During the present study it was also observed that breeding declined in the dry season. However, Ae. aegypti and Ae. albopictus were found mainly in the wet period of the year.

The monthly collected data of Aedes mosquitoes showed that 396 (57.47\%) mosquitos were identified as A. albopictus, 51 (7.02\%) were as A. aegypti and 242 (35.12\%) were other Aedes species. Among them 347 (50.36\%) were males and 342 (49.63\%) were females (Table 2).

Table 2. Month-wise distribution of Aedes species collected from the tree holes of different locations of Dhaka University Campus and Sohrawardi Park from January to December, 2010.

\begin{tabular}{lcccccc}
\hline \multicolumn{1}{c}{ Month } & $\begin{array}{c}\text { Aedes } \\
\text { albopictus }\end{array}$ & $\begin{array}{c}\text { Aedes } \\
\text { aegypti }\end{array}$ & $\begin{array}{c}\text { Other } \\
\text { species }\end{array}$ & $\begin{array}{c}\text { Male } \\
(\%)\end{array}$ & $\begin{array}{c}\text { Female } \\
(\%)\end{array}$ & Total \\
\hline January & 0 & 0 & 0 & 0 & 0 & 0 \\
February & 0 & 0 & 0 & 0 & 0 & 0 \\
March & 5 & 0 & 2 & 3 & 4 & 7 \\
April & 20 & 3 & 11 & 13 & 21 & 34 \\
May & 30 & 5 & 21 & 23 & 33 & 56 \\
June & 47 & 8 & 31 & 37 & 49 & 86 \\
July & 67 & 8 & 39 & 50 & 64 & 114 \\
August & 65 & 8 & 35 & 64 & 44 & 108 \\
September & 78 & 10 & 47 & 77 & 58 & 135 \\
October & 51 & 6 & 27 & 49 & 35 & 84 \\
November & 24 & 2 & 20 & 21 & 25 & 46 \\
December & 9 & 1 & 9 & 10 & 9 & 19 \\
\hline Total & $396(57.47)$ & $51(7.4)$ & $242(35.12)$ & $347(50.36)$ & $342(49.63)$ & 689 \\
\hline
\end{tabular}


The heights of tree holes and the percentage of the larvae found in the belonging holes are shown in Table 3. In the present study, it was found that the Aedes larvae were most frequent in the tree holes which were 20-40 inches in height. A total of 27 species of trees was searched from the four locations where 56 tree holes were visited and 34 positive tree holes of 17 species of trees were found. The largest number of larvae was found in the bamboo (Bambusa nutans) stump. Soman (1977) searched a total of 286 tree holes in Bangalore city, India and out of which 58 yielded mosquito larvae belonging to six different species; Ae. aegypti breeding was noticed in 26 tree holes and Ae. albopictus in 46 tree holes.

Table 3. Density of Aedes larvae on different types of plants surveyed (27 plants) along with their heights.

\begin{tabular}{|c|c|c|c|}
\hline Plant name & $\begin{array}{l}\text { Plant height } \\
\text { (inch) }\end{array}$ & $\begin{array}{c}\text { Total larvae } \\
\text { counted }\end{array}$ & $\%$ \\
\hline Artocarpus heterophyllus & 40 & 68 & 9.87 \\
\hline Anthocephalus chinensis & 10 & 35 & 5.07 \\
\hline Delonix regia & 28 & 13 & 1.89 \\
\hline Mangifera indica & 32 & 57 & 8.27 \\
\hline Musa sapientum & 40 & 35 & 5.07 \\
\hline Litchi chinenses & 40 & $\mathrm{x}$ & $\mathrm{x}$ \\
\hline Disopyros peregrine & 30 & 19 & 2.76 \\
\hline Cycas revolute & 25 & $\mathrm{x}$ & $\mathrm{x}$ \\
\hline Ravenala madagascariensis & 25 & 29 & 4.20 \\
\hline Moringa olifera & 40 & $\mathrm{x}$ & $\mathrm{x}$ \\
\hline Bambusa nutans & 29 & 160 & 23.22 \\
\hline Mimusops elengi & 35 & 25 & 3.62 \\
\hline Nyctanthes arbor-tristis & 30 & $\mathrm{x}$ & $\mathrm{x}$ \\
\hline Alocasia indica & 10 & $\mathrm{x}$ & $\mathrm{x}$ \\
\hline Callistemon citrinus & 23.5 & $\mathrm{x}$ & $\mathrm{x}$ \\
\hline Ployalthia longifolia & 28 & 15 & 2.18 \\
\hline Artabotryss uncinatus & 35 & 53 & 7.69 \\
\hline Hevea brasiliensis & 18 & 30 & 4.35 \\
\hline Alstonia scholaris & 10 & $\mathrm{x}$ & $\mathrm{x}$ \\
\hline Lagerstroemia speciosa & 24 & $\mathrm{x}$ & $\mathrm{x}$ \\
\hline Tamarindus indica & 32.5 & $\mathrm{x}$ & $\mathrm{x}$ \\
\hline Albizzia richardiana & 27 & 15 & 2.18 \\
\hline Barringtonia acutangula & 14 & $\mathrm{x}$ & $\mathrm{x}$ \\
\hline Phyllanthus emblica & 38 & 34 & 5.0 \\
\hline Syzygium jambos & 9 & 69 & 10.01 \\
\hline Syzygium cumini & 26 & 14 & 2.03 \\
\hline Accacia moniformis & 31 & 18 & 2.61 \\
\hline Total & & 689 & \\
\hline
\end{tabular}

The percentage of positive tree holes in which Aedes larvae were found in different location of Dhaka University Campus and Sohrawardi Park were 
identified $66.66 \%$ in the Curzon Hall, $75.0 \%$ in the Botanical Garden of the Curzon Hall Campus, $75.0 \%$ in the Arts Building and $50.0 \%$ in the Suhrawardi Park (Table 4). In this study, the highest number (28) of tree holes were observed in Suhrawardi Park (Table 4).

Table 4. Number of Aedes larvae in the positive tree holes of four different locations in Dhaka University Campus and Suhrawardi Park.

\begin{tabular}{lcccc}
\hline Locality & $\begin{array}{c}\text { No. of tree } \\
\text { holes visited }\end{array}$ & $\begin{array}{c}\text { Positive tree } \\
\text { hole }\end{array}$ & $\begin{array}{c}\text { Positive tree hole } \\
(\%)\end{array}$ & Total larvae \\
\hline Curzon Hall (DU) & 12 & 8 & 66.66 & 143 \\
Botanical Garden (DU) & 4 & 3 & 75.00 & 83 \\
Arts Building (DU) & 12 & 9 & 75.00 & 152 \\
Suhrawardi Park & 28 & 14 & 50.00 & 309 \\
\hline Total & 56 & 34 & & 689 \\
\hline
\end{tabular}

The types of debris collected from different tree holes and the number of larvae present in these holes are shown in Table 5. The number of tree holes with wet soil was three and with liquid was nine in Curzon Hall Campus; with wet soil was three, liquid was one in Botanical garden; with wet soil four and liquid eight in Arts Building Campus, and with wet soil 11, liquid 17 in Suhrawardi park. Out of 12, 4, 12, 28 tree holes, in which wet soil and liquid were present, Aedes positive tree holes were found 8, 3, 9, 14, respectively (Table 4).

Table 5. Number of Aedes larvae found in tree hole with the type of debris and localities.

\begin{tabular}{lccccc}
\hline \multicolumn{1}{c}{ Locality } & Wet soil & Liquid & $\begin{array}{c}\text { Total tree } \\
\text { hole }\end{array}$ & $\begin{array}{c}\text { Positive tree } \\
\text { hole }\end{array}$ & Total larvae \\
\hline Curzon Hall (DU) & 3 & 9 & 12 & 8 & 143 \\
Botanical Garden (DU) & 3 & 1 & 4 & 3 & 83 \\
Arts Building (DU) & 4 & 8 & 12 & 9 & 152 \\
Suhrawardi Park & 11 & 17 & 28 & 14 & 309 \\
\hline Total & 20 & 25 & 56 & 34 & 689 \\
\hline
\end{tabular}

Nasiruddin (1952) found Ae. aegypti in bamboo stumps and tree holes in Dhaka City. But, Barraud (1934) observed that it was unusual to find the larvae of Ae. aegypti in tree holes or banana stumps. Again, Basio (1971) found this species in both natural and artificial containers in the Philippines. It seems that it is the question of the availability of containers which regulate the choice of breeding places. There are a few plants and bamboo stumps available in Dhaka City now than in the 40's or 50's which might have compelled house loving mosquito to breed in artificial containers. It is also likely that water $\mathrm{pH}$ and pollution can also be the factors for attracting or inhibiting breeding of 
Aedes mosquitoes in both types of containers. Observers usually emphasized that clean water is essential for their breeding. Ae. albopictus was the only species found in all types of containers sampled. Similar findings were also noted by several workers in South-east Asia (Basio 1971, Huang 1979).

Environmental condition, such as rainfall and dry condition greatly influence the occurrence and distribution of the temporary habitat breeding mosquito species. Therefore, the seasonal changes bring about considerable change in the mosquito population composition of a given area. This is dependent on its humidity and precipitation. It follows naturally that the population of the species was high in some months during rainy season and then gradually began to decrease in other month of dry season. Previous reports suggested that Ae. aegypti was not found in tree hole. Most of them said that Ae. aegypti does not prefer tree hole habitats for egg laying. In the present study, it was observed that Ae. aegypti was found in tree hole habitats. From this survey it may be assumed that A. albopictus prefers the tree hole habitats for egg laying more than Ae. aegypti and due to the non-availability of its natural breeding habits Ae. aegypti also shifted to tree holes for its breeding purpose.

\section{LITERATURE CITED}

AHMAD, K. 2000. Bangladeshi Government appeals to WHO. Lancet 356(9227): 409.

AHMED, T.U. 1987. Checklist of the mosquitoes of Bangladesh. Mosq. Syst. 19(3): 187-200.

AHMED, T.U., RAHMAN, G.M.S., BASHAR, K., SHAMSUZZAMAN, M., SAMAJPATI, S., SULTANA, S., HOSSAIN, M.I., BANU, N.N. and RAHMAN, M.S. 2007. Seasonal prevalence of dengue vector mosquito in Dhaka City, Bangladesh. Bangladesh J. Zool. 35(2):205-212.

ALAVI, Y., ARAI, M., MENDOZA, J., TUFET-BAYONA, M., SINHA, R., FOWLER, K., BILlER, O., FRANKE-FAYARD, B., JNASE, C.J., WATER, A. and SINDEN, R.E. 2003. The dynamics of interactions between Plasmodium and the mosquito: a study of the infectivity of Plasmodium berghei and Plasmodium gallinaceum and their transmission by Anopheles stephense, Anopheles gambiae and Aedes aegypti. Int. J. Parasitol. 33: 933-943.

AZIZ, M.A., GRAHAM, R.R., GREGG, M.B. 1967. "Dacca fever"-an outbreak of Dengue. Pak. J. Med. Res. 6:83-92.

BARRAUD, P.J. 1934. The fauna of British India, including Ceylon and Burma. Diptera. Vol. 5, Family culicidae, Tribes Megar hinni and culicini. London. Xxxvii+463pp.

BASIO, R.G. 1971. The mosquito fauna of the Philippines (Diptera:Culicidae). Philipp. Nat. Mus. Mogr. 4:198.

CHAN, K.L., HO, B.C. and CHAN, Y.C. 1971. Aedes aegypti (L.) and Aedes albopictus (Skuse) in Singapore City. 5.Observation in relation to dengue haemorrhagic fever. Bull. World Health Organ. 44: 629-633.

CHEONG, W.H. 1986. The vector of dengue and dengue haemorrhagic fever in Malaysia. In: Rudnick, A., Lim, T.W., editors. Dengue fever studies in Malaysia, Malaysia: Institute of Medical Research, Kuala Lumpur, Bulletin 23:155-167.

CHRISTOPHER, S.R. 1960. Aedes aegypti (L.) the yellow fever mosquito, its life history. bionomics and structure. Cambridge University Press. London, $738 \mathrm{pp}$. 
CORDELlIER, R.M., GERMAN, J.P., HERVY E.T.J. and MOUCHET 1977. Guide partique pour l'etude des vecteur de fie'vre en Afrique et method de lutt. Initiation et Documentation technique, ORSTOM. Paris 114pp.

ERITJA, R.A., ESCOSA, R., LUCIENTES, J., MARQUE`S, E., MOLINA, R., ROIZ, D. and RUIZ, S. 2005. Worldwide invasion of vector mosquitoes: present European distribution and challenges for Spain. Biol. Invas. 7(1): 87 - 97.

GRATZ, N.G. 2004. Critical review of the vector status of Aedes albopictus. Med. Vet. Entomol. 18(3): 215-227.

GUBLER, D.J. 1998. Dengue and Dengue haemorrhagic fever. Clin. Microbiol. Rev. 11(3): 3480-3496.

GUBLER, D.J., REITER, P., EBI, K.L., YAP, W., NASCI, R. and PATZ, J.A. 2001. Climate variability and change in the United States: potential impacts on vector and rodent-borne diseases. Environ. Health Pres. 109 (Suppl 2):223-233.

HARRINGTON, L.C., EDMAN, J.D. and SCOTT, T.W. 2001. Why do female Aedes aegypti (Deptera: Culicidae) feed preferentially and frequently on human blood? J. Med. Entomol. 38: 411-422.

HAWLEY, W.A. 1988. The biology of Aedes albopictus. J. Am. Mosq. Control Assoc. suppl. 1: 1- 39.

HUANG, Y.M. 1979. Medical entomology studies-XI. The subgenus Stegomyia of Aedes in the Oriental region with keys to the species (Diptera: Culicidae). Contrib. Am. Entomol. Inst. 15(6): $1-79$.

JULIANO, S.A., O'MEARA, G.F., MORRILL, J.R., and CUTWA, M.M. 2002. Desiccation and thermal tolerance of eggs and the coexistence of competing mosquitoes. Oecologia 130(3): $458-469$.

KHAN, A.R. 1980. Studies on the breeding habitats and seasonal prevalence of larval population of Aedes aegypti (L.) and Aedes albopictus in Dacca City. Bangladesh Med. Res. Counc. Bull. 6(2): 45-52.

KNUDSEN, A.B. 1995. Global distribution and continuing spread of Aedes albopictus. Parassitologia 37: 91-97.

LEE, D.J., HICKS, M.M., GRIFFITHS, M., DEBENHAM, M.L., BRYAN, J.H., RUSSELL, R., GEARY, M. and MARKS, E. 1987. The culicidae of the Australian Region. Australian Government Publishing Service, Canberra. Vol. 5.

LOUNIBOS, L.P. 2002. Invasions by insect vectors of human disease. Annu. Rev. Entomol. 47: 233266.

MOORE, C.G. 1999. Aedes albopictus in the United States: current status and prospects for further spread. J. Am. Mosq. Control Assoc. 15(2):221-227.

NASIRUDDIN, M. 1952. Mosquitoes breeding in tree-holes and bamboo stumps in Dacca (East Pakistan). Pakistan. J. Hlth. 2: 110-112.

RAHMAN, M., RAHMAN, K., SIDDIQUE, A. K., SHOMA, S., KAMAL, A.H.B., ALI, K.S., NISALUK, A. and BREIMAN, R.F. 2002. First outbreak of dengue hemorrhagic fever, Bangladesh. Emerg. Infect. Dis. 8: 738-740.

RASUL, C.H., AHSAN, H., RASHID, A. and KHAN, M. 2002. Epidemiological factors of dengue hemorrhagic fever in Bangladesh. Indian Pediatr. 39(4): 369-372.

RUSSELL, P.K., BUESCHER, E.L., McCOWN, J.M., ORDONEZ, J. 1966. Recovery of dengue viruses from patients during epidemic in Puerto Rico and East Pakistan. Am. J. Trop. Med. Hyg. 15: 573-579.

RUSSEL, R.C., WEBB, C.E. and DAVIES, N. 2005. Aedes aegypti (L.) and Aedes polynesiensis Marks in Moorea Franch Polynesia: Adult population structure and pathogen (Wuchereria bancrofti and Dirofilaria immitis) infection rates indicate regional and seasonal epidemiological risk for dengue and filariasis. J. Med. Ent. 42: 1045-1056.

SOMAN, R.S. 1977. Studies on Aedes aegypti in Bangalore city. Indian J. Med. Res. 65: 8-16. 
THAVARA, U., TAWATSIN, A., CHANSANG, C., KONG-NGAMSUK1, W., PAOSRIWONG, S., BOONLONG, J., RONGSRIYAM, Y. and KOMALAMISRA, N. 2001. Larval occurrence, oviposition behavior and biting activity of potential mosquito vectors of dengue on Samui Island, Thailand. J. Vector Ecol. 26(2): 172-180.

WHO. 1995. Identification key of the larvae of Aedes sp. from Florida Medical Entomology Laboratory. Weekly Epidemiological Record No. 3 and 4. 17-32 pp.

(Manuscript received on May 31, 2012; revised on June 26, 2012) 